\title{
Evaluation of mobile phone radiation-induced structural changes of rat brain with emphasis on the possible protective role of pomegranate peel extract
}

\author{
S.K.M. Belal ${ }^{*}$, O.K. Afifi ${ }^{2}$, A.A. Afeefy ${ }^{3}$ \\ ${ }^{1}$ Department of Anatomy, College of Medicine, Taif University, KSA \& Department of Anatomy, Faculty of Medicine \\ [Assiut branch], Al-Azhar University, Egypt \\ ${ }^{2}$ Department of Anatomy, College of Medicine, Taif University, KSA \& Department of Histology, Faculty of Medicine, \\ Tanta University, Egypt \\ ${ }^{3}$ Department of Physical Therapy, College of Applied Medical Sciences, Taif University, KSA\& Anatomy Department, \\ Faculty of Medicine [female section], Alazhar University, Egypt
}

\section{- Original article}

\section{*Corresponding authors: \\ Saied K.M. Belal Ph.D., \\ E-mail:}

drsaiedbelal@yahoo.com

Revised: October 2019

Accepted: January 2020

Int. J. Radiat. Res., October 2020;

18(4): $753-764$

DOI: 10.18869 /acadpub.ijrr.18.4.753

\begin{abstract}
Background: The study aims to evaluate the impact of the antioxidant rich pomegranate fruit grown in Taif on the histological and immunohistochemical changes in the cerebral and cerebellar cortex after different levels of mobile exposure. Materials and Methods: Thirty adult male rats were divided into group I, II, III; IV, and group V. Group I was control and group II rats were exposed to $900 \mathrm{MHz}$ and in group III the rats are exposed to $1800 \mathrm{MHz}$ for two months. Group IV the rats were exposed to $900 \mathrm{MHz}$ concomitant with pomegranate peel extract $(500 \mathrm{mg} / \mathrm{kg})$ and group $\mathrm{V}$ rats were exposed to $1800 \mathrm{MHz}$ and pomegranate peel extract $(500 \mathrm{mg} / \mathrm{kg}$ ) orally in aqueous solution once per day for two months. Frontal cortex and cerebellum tissues were dissected out and processed for histopathological and immunohistochemical studies. Results: The cerebral and cerebellar cortexes of mobile-exposed rats exhibited degenerative changes especially in the nerve cells. These changes were more pronounced with increase in the frequency of radiation. Most of pyramidal and Purkinje cells became irregular in shape, had deeply stained nuclei, and were surrounded with peri-cellular haloes and vacuolated neuropil. However, some of them were surrounded with neuroglial accumulation. Conclusion: The study concluded that pomegranate peel extract can ameliorate the histopathological changes induced by mobile phone electromagnetic radiations.
\end{abstract}

Keywords: Mobile phone, rats, cerebral cortex, cerebellum, pomegranate peel extract.

\section{INTRODUCTION}

The effects of electromagnetic radiation (EMR) emitted by mobile phones on the CNS have become a particular concern, owing to its close proximity to the brain (1). Few studies have shown significant impact of EMR on sleeping patterns and cognitive function $(2,3)$. A reversible EEG and regional cerebral blood flow that measure the brain function depict the alteration within the pulsed radiofrequency (4). Moreover, it was reported that short-term memory loss or other cognitive effects may be associated with the use of mobile telephones (5) and there are connections between EMR exposure and cancer (6). Other study shows that EMR may cause behavioral changes as evidenced by a reduction in locomotor activity, increased grooming, and freezing behavior. In general, EMR exposure may have detrimental effects on the body, depending on its frequency and power (7). Analogue phones use frequencies of $400-450 \mathrm{MHz}$, and digital 
mobile phones use frequencies of $850-900 \mathrm{MHz}$ and $1850-1990 \mathrm{MHz}{ }^{(8)}$. The higher frequency means that they emit much more EMR (9). It was found that $900 \mathrm{MHz}$ radiation emitted from mobile phones do not affect p53 apoptotic parameters (10). Furthermore, adverse reactions including neuronal damage in the brain, DNA mutations, deterioration of blood-brain barrier permeability, and tumor development are likely to occur as a result of increased exposure to EMR (11).

The exact mechanism by which EMR induced neurotoxicity is not evident. It was found that the mobile phone radiation can increase the phosphorylation and activation of heat shock protein-27 (hsp27). The activation o hsp27 promotes brain cancer by inhibiting the cytochrome-caspase-3 apoptotic pathway and enhance the permeability of the blood-brain barrier by stabilizing stress fibers of endothelial cells (12). In addition, EMR causes oxidative stress that induces apoptosis. The signal for apoptosis is possibly generated via lipid peroxidation as the radiation acts on cell membranes (13). The EMR can also create oxidative stress by triggering free radicals (14).

Pomegranate, Punicagranatum L. (Punicaceae), is a shrub native to the Mediterranean region and is a native fruit to Al-Taif region (15). The whole pomegranate fruit, its peel, or leaf extracts have powerful antioxidant and anti-lipo -peroxidative activities (16). Furthermore, it exhibits antioxidant activity accompanied with ionizing radioprotective and antifibrotic properties (17). Pomegranate-derived products have shown beneficial effects on the treatment and prevention of various diseases, such as cancer, cardiovascular disease, neurological disorders, diabetes, colon inflammation, and other diseases $(18,19)$. Pomegranate extract has no side effects and no known drug interactions; therefore, it is considered as the most potent way to prevent cancer (20), strengthen the immune system, protect heart (21), promote wound healing, and strengthen the connective tissue (which may keep cancer cells from spreading) (22). Its protective role has also been studies based on fatty liver among the obese individuals through improvement of abnormal lipid metabolism (23).

The antioxidant activity of pomegranate juice is threefold higher than that of red wine or green tea (24). Clinical studies showed that pomegranate juice possesses a higher antioxidant capacity than apple juice (25). The safety of pomegranate and its constituents have been studied experimentally and clinically and no evidence was observed for toxic effects on body organs including heart, liver, and kidney (26). Maternal consumption of pomegranate juice in the drinking water protected against experimental neonatal hypoxic brain injury (27). Moreover, pomegranate extract showed neuroprotective effects against Alzheimer's disease and depression (28). It is necessary for many critical roles in the CNS as astrocyte-neuron interactions, cell-cell communication, adjusting the filament network during mitosis, and CNS repair after injury (29).

Pomegranates contain very high levels of antioxidant substances, as compared to other fruits and vegetables. Although, many studies suggested that the cellular phones change the functional activity of CNS especially the memory and cognitive function, only few studies have shown the changes occurring at histological level either in cerebral cortex or cerebellum. Moreover, there is no specific protection against the radiation emitted mobile phones up till now. Therefore, the present study has evaluated the histological and immunohistochemical (GFAP) changes of different level EMR exposure on the cerebral cortex and cerebellum in adult rats. This was conducted to evaluate the possible protective role of pomegranate peel extract as a commonly native fruit in Al-Taif region.

\section{MATERIALS AND METHODS}

\section{Animals}

Thirty adult male Spraque-Dawley rats (8-week-old, 150-200 g body weight) were placed in clean properly ventilated cages under similar conditions. The study was conducted according to the guidelines of the Animal Care and Use Committee of National Research Center. The rats had free access to laboratory balanced

Int. J. Radiat. Res., Vol. 18 No. 4, October 2020 
diet with adequate water supply. The rats were randomly divided into five groups (6 rats each);

- Group I was considered as a control and was subdivided into 2 equal subgroups; 3 animals each. Subgroup Ia in which each rat was held in the EMR chamber for 60 minutes a day for 60 days (two months) under the same environmental conditions without exposure to EMR. Subgroup Ib in which each rat was given pomegranate peel extract $(500 \mathrm{mg} / \mathrm{kg})$ orally in aqueous solution once per day orally for two months (15).

- EMR groups included group II in which the rats were exposed to $900 \mathrm{MHz}$, and group III in which the rats are exposed to $1800 \mathrm{MHz}$ for two months.

- Group IV the rats were exposed to $900 \mathrm{MHz}$ concomitant with pomegranate peel extract $(500 \mathrm{mg} / \mathrm{kg})$ orally in aqueous solution once per day for the two months.

- Group V rats are exposed to $1800 \mathrm{MHz}$ and pomegranate peel extract $(500 \mathrm{mg} / \mathrm{kg})$ was administrated at the same time orally in aqueous solution once per day for two months.

\section{Exposure technique}

Animals of group II and III were exposed to EMFs emitted from mobile phones. Group II was exposed to one mobile phone ( $900 \mathrm{MHz})$; while, group III was exposed to two mobile phones $(1800 \mathrm{MHz})$ at the same time. Each rat was exposed for 60 minutes per day for 60 days from 8:00-12:00 a.m. During EMFs exposure the plastic cages are arranged in a circular manner and the mobile phones were placed in the center (30).

\section{Preparation of pomegranate peels extract}

Fresh mature Punicagranatum L. (Punicaceae) fruits are used. The taxonomic identity of the plant was prepared by the Biology department, College of Science, Taif University. For extraction purpose, a peel was removed and dried in shade for 10 days before grounding. The grounded material (50 g) was shaken in $500 \mathrm{ml}$ of absolute methanol for 24 hours at room temperature, followed by filtration through four layers of gauze. The filtrate was centrifuged at $8000 \mathrm{rpm}$ for $15 \mathrm{~min}$. The clear supernatant was collected, and then the methanol was evaporated in a rotary evaporator at $45{ }^{\circ} \mathrm{C}$ under reduced pressure. Crude extract $(23.5 \%, \mathrm{w} / \mathrm{w})$ was kept at $20{ }^{\circ} \mathrm{C}$ till further using. Pomegranate peel extract $(500 \mathrm{mg} / \mathrm{kg})$ was administered orally in aqueous solution once per day (31).

\section{Histopathologic Evaluation}

At appropriate time, the animals were anesthetized using ether inhalation and perfused with $4 \%$ paraformaldehyde in $0.1 \mathrm{M}$ sodium phosphate buffer containing $2.5 \%$ glutaraldehyde solution. Then, they were decapitated by a curved sharp scissor and their brains were removed by dissecting the skull bones from behind with some blunt forceps starting from the vertebral canal to the frontal bone. The brains were kept in formalin for twenty-four hours and each brain was divided sagittal into right and left hemispheres using a sharp blade. Frontal cortex and cerebellum tissues were dissected out and processed for histopathological and immunohistochemical studies (32).

\section{Immunohistochemistry}

$4 \mu \mathrm{m}$ paraffin sections were used for GFAP immune-staining activity with Streptavidinbiotin immune-peroxidase technique. The sections were placed on pretreated organo-silane slides and were deparaffinized and rehydrated. The endogenous peroxidase activity was blocked by using $0.05 \% \mathrm{H} 2 \mathrm{O} 2$ in absolute methanol for 30 minutes, followed by three washes in phosphate buffer saline (PBS). Antigen retrieval was performed by heating it in citrate buffer (pH6) in microwave (4 minutes at high pressure then 4 at low pressure). Nonspecific binding of the primary antibody was prevented by pre-incubation in 1-5\% normal bovine serum albumen dissolved in PBS for 30 minutes at $37^{\circ} \mathrm{C}$. Later, the sections were incubated with optimally diluted GFAP mouse monoclonal antibody (Dako N-series Ready; 1r antibody). The slides were rinsed in PBS and the secondary antibody (horse antimouse) was applied to it. After that, the immunostaining was amplified and completed by Hoarseradish Peroxidase complex (DakoREALTMEn Vision 
TM/HRP, Mouse ENV) for 30 minutes. Sections were developed and visualized using 3,3 diaminobenzidine (DAB Chromogen). Sections were counterstained with Maye's haematoxylin, dehydrated, cleared in xylene, and over slipped with Permount. The negative control was performed using the PBS instead of primary antibody to check the specificity of the immunostaining. The Sections were examined under Olympus light microscope that was equipped with a digital photo-micrographic camera system. Moreover, the reactions were considered positive if there was dark brown cytoplasmic staining (32).

\section{RESULTS}

\section{Results of Cerebral cortex Histological results}

Microscopic examination of H\&E stained sections obtained from the control cerebral cortex of all non-exposed, and pomegranate peel extract treated rats were similar. The slides revealed the well-known normal histological structure specific for cerebral cortex. They showed that the cortex was formed of six layers from outside to inwards merged with each other and not highly demarcated (figure 1A). The pyramidal cells, granule cells, and neuroglia were the commonest cells inside all the layers. The pyramidal cells were pyramidal in shape and had open face nuclei, basophilic cytoplasm, and long apical dendrites. The granule cells were small polygonal cells with open face nuclei and prominent nucleoli. The neuropil that is a mat of neuronal and glial cell processes appeared as pink stained background (figure 1B).

Examination of H\&E stained sections obtained from $900 \mathrm{MHz}$ exposed animals (group II) revealed focal changes in all layers of the cortex as compared to the control group. Majority of the nerve cells were shrunken with loss of their processes and had peri-cellular halos. The blood vessels were more dilated than the control group. The pyramidal cells were more affected as they had lost their processes and became irregular in shape (figure 1C). The animals of group III exposed to higher level of EMR (1800 MHZ) showed more severe degenerative changes in the nerve cells and vacuolation of neuropil in all layers along with dilatation and congestion of many blood vessels. Regarding the pyramidal cells, they were more or less still pyramidal in shape, but they had deeply stained nuclei. Most of granule cells were crowded and surrounded with darkly stained neuroglial cells. Both cells had peri-cellular halos were surrounded with vacuolated neuropil (figure 1D).

Examination of cerebral cortex specimens obtained from animals treated with pomegranate peel extract, concomitantly with $900 \mathrm{MHz}$ exposure showed improvement in nerve cells in many areas (Figure 1h). The peri-cellular or neuropil vacuolation were decreased and the blood vessels were more dilated than the control group; however, it was less dilated than the animals exposed to 900 MHZ. Majority of the granule cells, unlike control group showed open face nuclei and prominent nucleoli; while, occasional cells were shrunken and had darkly stained nuclei. Occasional pyramidal cells were still affected in between the normal granule cells. They were shrunken, had darkly stained nuclei and surrounded with peri-cellular halos (figure 1E). Examination of specimens obtained from animals treated with pomegranate peel extract concomitantly with $1800 \mathrm{MHz}$ exposure showed dilated and congested blood vessels; however, they were less vacuolation than the corresponding group without protection (group III). Majority of the granule cells were nearly normal with open face nuclei and prominent nucleoli; while, the pyram ideal cells were normal in shape but had dark nuclei and were surrounded with peri-cellular halos (figure $1 \mathrm{~F}$ ).

\section{Immuno-histological results}

Concerning the GFAP immunoreactivity, it was detected that the cerebral cortex sections of control group showed a positive immunoreaction in the form of thin and regular brown staining fibers in the star shaped astrocytes (figure 3A). Examination of animals of group II (900 $\mathrm{MHz}$ exposure) showed an

Int. J. Radiat. Res., Vol. 18 No. 4, October 2020 
apparent increase in GFAP immunoreactive astrocytes, glial fibers. These fibers were appeared twisted with an irregular course and increase in their staining intensity. In the group III $(1800 \mathrm{MHz}$ exposure $)$, the GFAP immunoreactivity, was more increased in the astrocytes as compared to the previous group (figure 3B). Comparing with group II, examination of the immunoreactivity in animals of group (IV), showed an apparent decrease in the amount and intensity of GFAP immunoreactivity in the astrocytes. Comparing with group III, the GFAP immunoreactive sections from animals of group $\mathrm{V}$, was decreased (figure 3C). However, this was not the case in the control group.

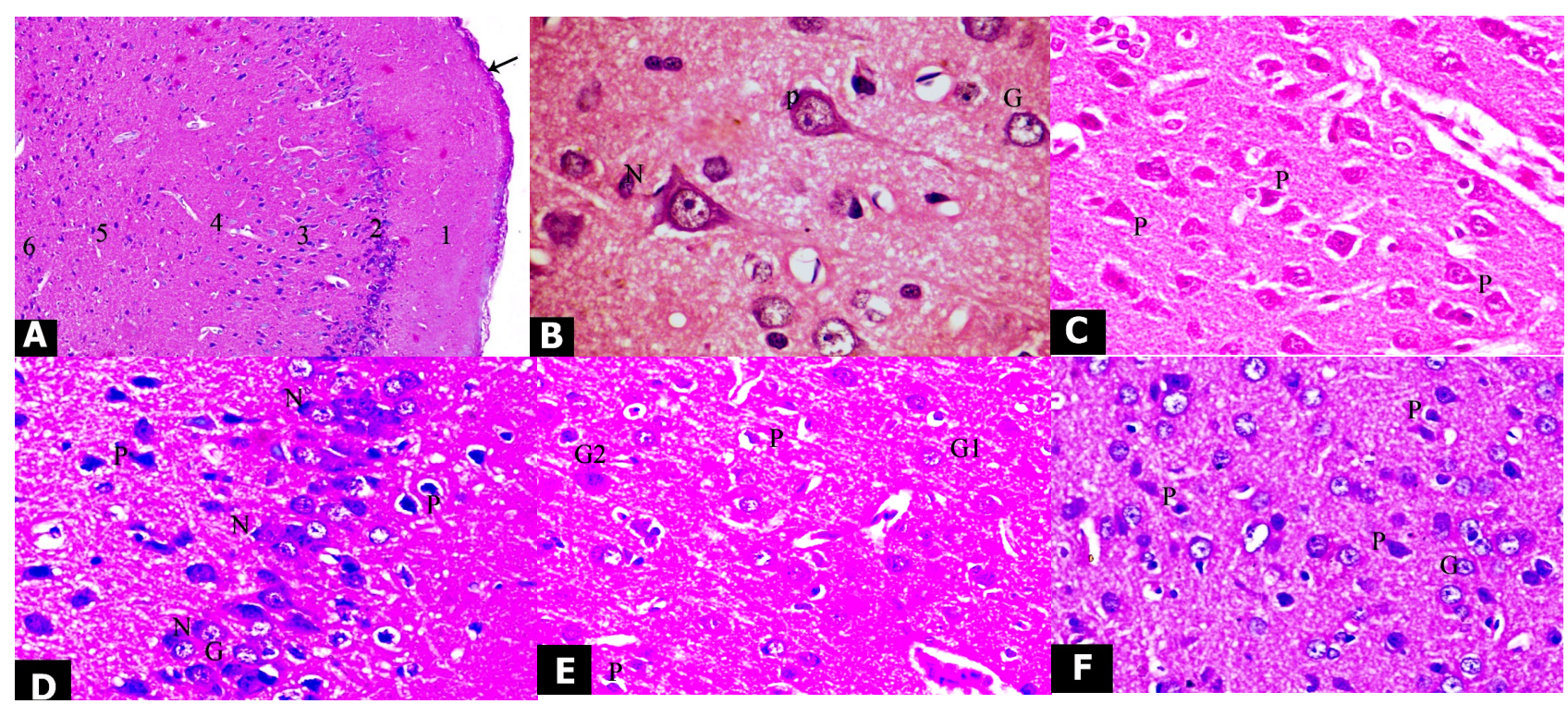

Figure 1. Photomicrographs of sections in the cerebral cortex of adult rat:

(A) a section of control animal showing: general histological structure of the cerebral cortex, pia matter [arrow], molecular layer [1], outer granular layer [2], outer pyramidal layer [3], inner granular layer [4], inner pyramidal layer [5] and the multiform layer [6] $\{H \& E$ 100X\}; (B) a section of control animal showing: pyramidal cell [P] and granule cell [G] with pale open face nucleus and neuroglia $[\mathrm{N}]$ with dense nuclei $\{\mathrm{Hx \& E} X 1000\}$; (C) exposed to electromagnetic field $900 \mathrm{MHZ}$ showing: shrunken irregular pyramidal cells with loss of their processes [P]. Notice the pericellualr and perivascular vacuolation $\{H \& E 400 X\}$; (D) exposed to electromagnetic field $1800 \mathrm{MHZ}$ showing: pyramidal cells with deeply stained nuclei and peri-cellular halos [P], accumulated area with granule cells $[G]$ surrounded with darkly stained neuroglial cells $[N]\{H \& E 400 X\}$; (E) treated with pomegranate peel extract,

concomitantly with electromagnetic field exposure, $900 \mathrm{MHZ}$, showing many granule cells [G1] with open face nuclei and prominent nucleoli, and few of them are shrunken [G2] with had darkly stained nuclei. The pyramidal cells are shrunken [P], and surrounded with peri-cellular halos $\{\mathrm{H} \& \mathrm{E} 400 \mathrm{X}\}$; (F) treated with pomegranate peel extract, concomitantly with electromagnetic field exposure, $1800 \mathrm{MHZ}$, showing pyramidal cells [P] with dark nuclei among granule cells [G] more or less as in control group. Notice the peri-cellular halos around the pyramidal cells $\{H \& E 400 X\}$.

\section{Results of cerebellum Histological results}

$H$ \& E stained sections of the cerebellar cortex of the control group (subgroups a and b) showed well-known normal histological structure. They showed three distinct layers from outside to inwards; the molecular layer, the Purkinje cell layer, and the granular cell layer. The granular cell layer revealed regular thickness all over its length (figure 2A). The characteristic Purkinje cells were arranged in one row between the molecular and granular layers. They showed large pyriform cell bodies and centrally located vesicular nuclei with apparent nucleoli. The granular layer was composed of closely packed numerous small granule cells with dark spherical nuclei (figure 2B). Examination of sections of the group II exposed to $900 \mathrm{MHz}$, revealed multifocal neuronal affection especially on the granular and Purkinje cell layers. The thickness of the granular layer was irregular, as it was 
apparently decreased in some areas and increased in others (figure 2C). The monolayer arrangement of Purkinje cells was disrupted since many areas; as they showed either bilayer arrangement or disappeared completely. Few areas were severely affected as they showed disturbed architecture and vacuolated areas in the site of Purkinje cells and deeply dark granule cells. Majority or the areas were less affected and revealed monolayer of Purkinje cells surrounded by halos. However, some were shrunken and irregular; while, few still had pyriform shape (figure 2C).

The $H$ \& E stained sections of the rats are exposed to $1800 \mathrm{MHz}$ (group III) were severely affected. The granular layer was regular but was decreased in its thickness all over its length (figure 2D). Majority of Purkinje cells lost their process, were shrunken, and had irregular outlines with deep homogenous eosinophilic cytoplasm. They were surrounded with vacuolated neuropil (perineural spaces) with accumulation of neuroglial cells around some of them. Regarding their nuclei, few cells showed vesicular nuclei, others had pyknotic nuclei, and few showed complete loss of their nuclei (karyolysis). Some areas in the sections of this group showed multilayer of abnormal shrunken Purkinje cells, some of cells had homogenous nuclei with absence of any nuclear details, and others had deep pyknotic nuclei. Multiple vacuolated areas associated with increased microglial nuclei were observed in molecular layer; while, the granular layer showed many vacuoles and cells with pyknotic nuclei. The neuropil was vacuolated and most of cells in the molecular layer were surrounded by halos (figure 2D).

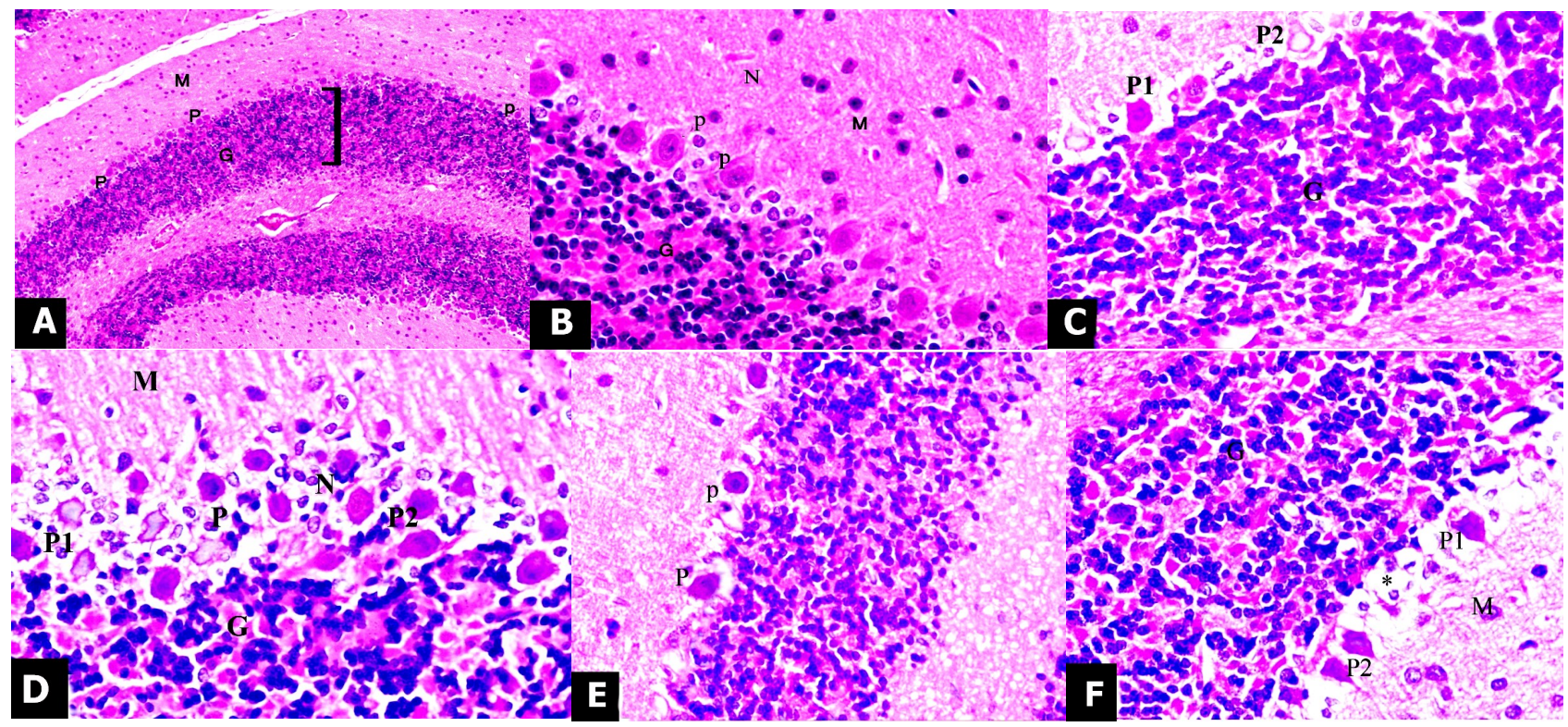

Figure 2. Photomicrographs of sections in the cerebellar cortex of adult rat: (A) a section of control animal showing: molecular cell layer [M], Purkinje cell layer [P], and granular cell layer. Notice the regular thickness of the granular cell layer all over its length $\{$ H\&E X 100\}; (B) a section of control animal showing: monolayer of pyriform shaped Purkinje cells with central vesicular nuclei and apparent nucleoli [P] and closely packed numerous granule cells with dark spherical nuclei [G]. Notice the molecular layer [M] and acidophilic neuropil [N]. \{H\&E X 400\}. (C) exposed to electromagnetic field, $900 \mathrm{MHz}$, showing: one layer of monolayer of Purkinje cells, some are distorted [P1] lose their process and other are still pyriform [P2]. Both types are surrounded with perinuclear halos

\{H\&E X 400\}; (D) exposed to electromagnetic field, $1800 \mathrm{MHz}$, showing: many layers of irregular, distorted Purkinje cells [P] in between outer molecular [M] and inner granular [G] layers. The surrounding neuropil is highly vacuolated and many neuroglial cells

$[\mathrm{N}]$ accumulate around Pukinje cells. Some Purkinje cells have homogenous nuclei with absence of any nuclear details [P1] and others had deep pyknotic nuclei [P2] \{H\&E X 400\}; (E) treated with pomegranate peel extract, concomitantly with electromagnetic field exposure, $900 \mathrm{MHZ}$, showing: area with still affected Purkinje cells [P]; as they lose their process and are surrounded with vacuolated neuropil $\{\mathrm{H} \& \mathrm{E} 400 \mathrm{X}\}$; (F) treated with pomegranate peel extract, concomitantly with electromagnetic field exposure, $1800 \mathrm{MHZ}$, showing: some still affected Purkinje cells still in between many apparently less affected cells [P2]. Notice vacuolated neuropil [*], molecular [M] and granular [G] layers more or less as the control $\{\mathrm{H} \& \mathrm{E} 400 \mathrm{X}\}$. 
Examination of specimens obtained from animals of group (IV) treated with pomegranate peel extract and concomitantly with $900 \mathrm{MHz}$ exposure showed improvement in nerve cells in many areas as comparted to group (II) that was exposed to $900 \mathrm{MHz}$ but not receive pomegranate. All sections showed monolayer arrangement of Purkinje cells between the molecular and granular layers. The granular layer was regular in thickness and more or less as in control group (figure 2E). Few Purkinje cells were still affected as they lost their process and were surrounded with small areas of vacuolated neuropil (figure 2E). Examination of sections of the group (V) which exposed to 1800 $\mathrm{MHz}$ and treated with pomegranate peel extract revealed a monolayer of Purkinje cells and a regular granular cell layer (figure 2F). Few Purkinje cells were affected in between of many apparently normal cells with central open face nuclei. Many cells were surrounded with highly vacuolated neuropil. The molecular and granular layers were more or less similar to control group (figure $2 \mathrm{~F}$ ).

\section{Immuno-histological results}

The immune-histochemical results revealed that the cerebellar cortex sections of control group showed a positive GFAP immunoreaction in the molecular and granular layers of cerebellar cortex. The reaction was noticed in the form of thin and regular brown fibers in the star shaped astrocytes (figure 3D). Examination of the cerebellar cortex of the animals of group II (900 MHz exposure) showed an apparent focal increase in the amount and intensity of GFAP immuno-reaction in the molecular layer and in-between the granular cells. The glial fibers were twisted with an irregular course and had more intensely staining as compared to the control group. In the group III $(1800 \mathrm{MHz}$ exposure), the GFAP immunoreactivity was increased in all area of molecular layer and also in-between the granular cells (figure 3E). Comparing with group II, examination of the immunoreactivity in animals of group (IV), showed an apparent decrease in the amount and intensity of GFAP immunoreactivity, especially in the granular layer; however, it did not reach the control group. The molecular layer showed apparently moderate reaction. Comparing with group III, the GFAP immunoreactive sections from animals of group $\mathrm{V}$, was decreased and became more or less similar to the control group (figure 3F).

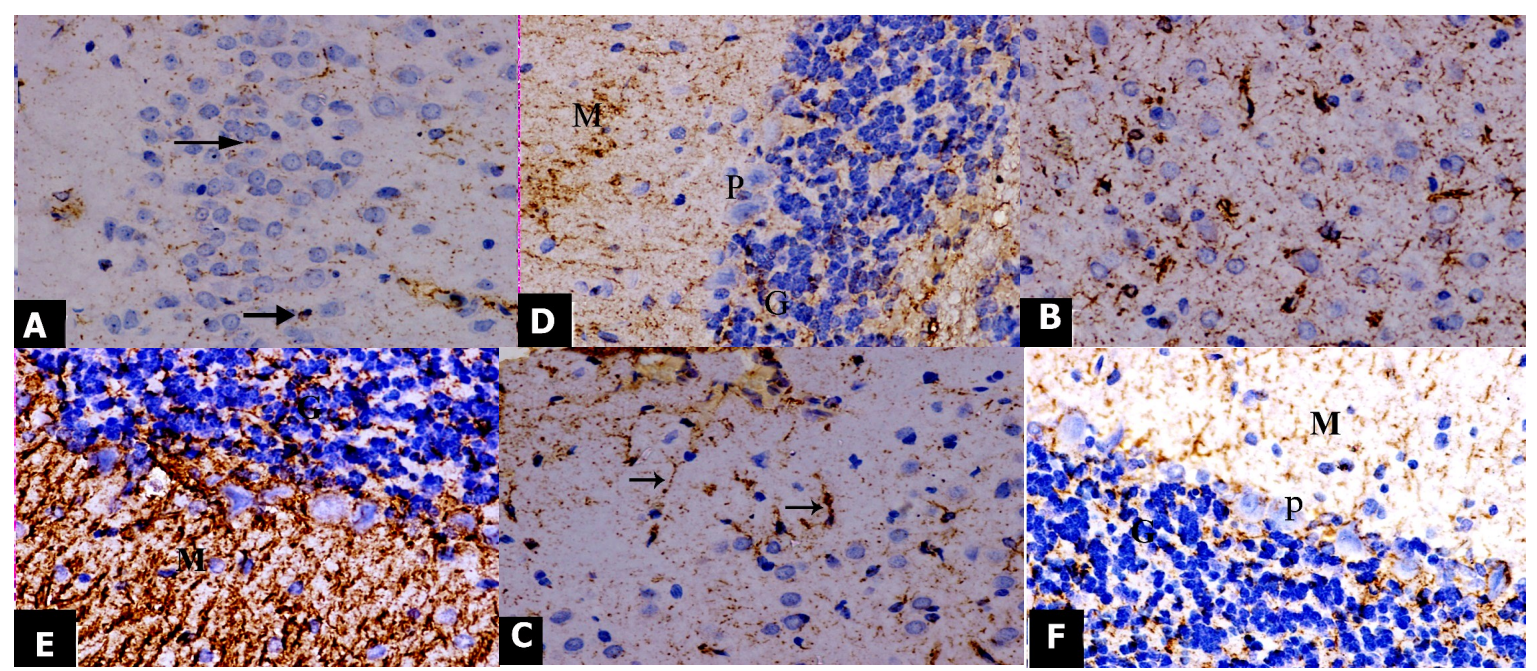

Figure 3. Photomicrograph of the GFAP immunostaining sections in adult rat's cerebral and cerebellar cortices: (A) cerebral cortex of control animal showing: a positive GFAP immunoreaction in the form of thin and regular brown staining fibers in the star shaped astrocytes [arrow] in the control animals. \{H\&E 400X\}; (B) cerebral cortex of animal exposed to electromagnetic field 1800 MHZ showing: more apparently increase of GFAP reaction in the astrocytes than the previous group $\{\mathrm{H} \& \mathrm{E} 400 \mathrm{X}\}$; (C) cerebral cortex of animal treated by pomegranate peel extract with exposure to $1800 \mathrm{MHZ}$ showing: decrease in the GFAP reaction [arrow] comparing with animals of group III in $\{H \& E$ LOOX $\}$. (D) cerebellar cortex of control animal showing; a positive GFAP reaction in the molecular [M] and granular [G] layers of in the form of thin and regular brown fibers in the control animals. Notice negative reaction in the Purkinje cell layer [p] $\{\mathrm{H} \& \mathrm{E} 400 \mathrm{X}\}$; (E) cerebellar cortex of animal exposed to electromagnetic field $1800 \mathrm{MHZ}$ showing: more diffuse increase of GFAP reaction in all area of molecular layer [M] and also in between the granular cells[G] $\{\mathrm{H} \& \mathrm{E}$ 400X\}; (F) cerebellar cortex of animal treated by pomegranate peel extract with exposure to $1800 \mathrm{MHZ}$ showing : a decrease in GFAP reaction to become more or less as in control animals in the molecular [M] and granular[G] layers of in the form of thin and regular brown fibers. Notice also negative reaction in the Purkinje cell layer [P] $\{\mathrm{H} \& \mathrm{E} 400 \mathrm{X}\}$. 


\section{DISCUSSION}

The widespread use of wireless mobile communication has raised concerns of adverse effect to the brain owing to its proximity to the electromagnetic field (EMF) emitted by mobile phones while using. The potential adverse effects of EMF exposure on the human CNS are still controversial (33); although, numerous studies have been carried out in the epidemiology, cellular biology, and toxicology research fields. In the present study, the microscopic examination of $\mathrm{H} \& \mathrm{E}$ stained cerebrum and cerebellum sections obtained from $900 \mathrm{MHz}$ exposed animals (group II) showed focal degenerative changes with disturbed architecture. These results were consistent with few studies that found many adverse effects and severe degenerative histological changes of mobile phone use on the human brain and brain related tissues, such as cerebellum and hippocampus $(1,34,35)$.

The Cho and lactate levels were high with a single-dose irradiation for 12 months in the damaged region of the brain tissue of rats (36). Moreover, the number of apoptotic cells was significantly different between EMR exposed rats as compared to the control ones (37). These changes were explained by hypothesis of oxidative stress. The increased oxidative stress led to increased apoptotic process (programmed cell death) (38). However, the antioxidant system of the organism created various responses against the oxidative stress produced by ROS (39. 40). The free radicals at a low level of intensity might enhance the antioxidant defense system through the stimulation of gene expression of antioxidant enzymes; while, the free radicals at a high level might exceed the capacity of the antioxidant defense system because of oxidant damage (41). However, another study found that EMR exposure did not show any difference in CAT and GSH-Px levels in the brain tissue of rats. These controversial results may be related to the implementation time and dose differences (42).

The degenerative cells of brain after exposure to electromagnetic waves were attributed to increased permeability of the blood brain barrier (BBB). The BBB acted as a shield that protected the brain against many harmful substances, and its disruption might account for the damage of brain tissue $(43,44)$. They are indicative of neuronal death and are consistent with neuronal necrosis as observed in early stages of ischemic, hypoxic/ischemic, hypoglycemic, and excito-toxic states (45). Based on these explanations, the most accepted theory for the cerebrum and cerebellum injury after mobile phone exposure is the oxidative injury.

In this study, the rats treated with pomegranate peel extract demonstrated a significant neuroprotection from electromagnetic field emitted by mobile phone injury. Examination of cerebral cortex and cerebellum specimens obtained from animals treated with pomegranate peel extract, concomitantly with $900 \mathrm{MHz}$ (low intensity) exposure showed improvement in nerve cells in many areas. These results were consistent with few studies that depicted pomegranate as a neuroprotective agent and attributed the beneficial activities of pomegranate to its active constituents including; polyphenols, flavonoids, and tannins $(30,46)$.

There was a correlation between the role of pomegranate peel extract and juice in regulating vital cellular functions, including cell proliferation and differentiation $(47,48,49)$. Also, it has been shown to have a variety of protective effects in several disease models including reduced low-density lipoprotein aggregation, oxidative stress, amyloid load, and improved cognitive behavior $(50,51)$. The presence of polyphenols in the pomegranate peel may be responsible also for anti-inflammatory and anti-carcinogenic effect of peel extracts $(24,52)$.

Catechins (another constituent of pomegranate juice) have been shown to increase intracellular glutathione (GSH) levels and modulate glutathione peroxidase activity. Its depletion is the first indicator of oxidative stress during neurodegeneration (53). The dietary supplementation of pomegranate prevented the reduction of SOD and CAT activities that were significantly diminished in oxidative stress. This result assured that the neuroprotective effects of pomegranate might be due to its antioxidant

Int. J. Radiat. Res., Vol. 18 No. 4, October 2020 
activity (54).

Pomegranates tend to improve $\mathrm{Na}+\mathrm{K}+$ -ATPase activity, as its multiple bioactive compounds such as phenolic acids, flavonoids, tannins, anthocyanins, ascorbic acid, ellagic acid, gallic acid, fumaric acid, caffeic acid, catechin, Epigallocatechingallate, quercetin, rutin, tannins, and alkaloids have multiple functions, making it pharmacologically complex (53). This reduction may occur by directly neutralizing the generated reactive oxygen species, increasing certain antioxidant enzyme activities, inducing metal chelation activity and reducing resisting formation (54).

These results might be explained as the glial cells, which are sensitive to electromagnetic waves. Some special astrocytes were suggested to provide a unique neurogenic niche and have the capability to promote proliferation and neuronal fate determination (55). Moreover, in response to central nervous system injury, the astrocytes become reactive and increase their expression of the intermediate filament proteins glial fibrillary acidic protein (GFAP) (56). The increase in GFAP could be also explained by an increase in the astrocytes that provide more nourishment required by the injured neurons. Other studies described a population of small cells, which were derived from the astrocytes and probably function as a transient precursor in the formation of new neurons $(57,58)$.

Flavonoid (the main constituent of pomegranate) has been observed to inhibit NO, IL-1b and TNF-a production in activated microglia cells. They inhibit iNOS and cyclooxygenase (COX-2) expression, NO production, cytokine release, and NADPH oxidase activation and subsequent reactive oxygen species generation, in astrocytes and microglia (59). They induce beneficial effects on the vascular system leading to changes in cerebrovascular blood flow capable of causing angiogenesis, neurogenesis, and changes in neuronal morphology (60).

\section{CONCLUSION}

The study concluded that pomegranate peel extract provided protection against the neurotoxic effects of mobile phone radiation either in the cerebral or cerebellar cortex in an experimental model of adult male albino rats. The mechanisms of protection may be related to their antioxidant activity. As the pomegranates are grown in Taif, it is recommended that awareness should be focused on pomegranate as an important natural antioxidant protective therapy for the mobile phone neurotoxicity. Further intensive experimental and clinical study may be required to adjust the dose and form of pomegranate treatment considering the mild degenerative changes still observed in some cells in this work.

\section{ACKNOWLEDGEMENT}

The authors are very thankful to all the associated personnel in any reference that contributed in/for the purpose of this research. Furthermore, this research is not funded through any source.

\section{Funding}

This research was supported by Taif University, Saudi Arabia [grant number 1-436-4315].

Conflicts of interest: Declared none.

\section{REFERENCES}

1. Dubreuil D, Jay T, Edeline J (2003) Head-only exposure to GSM900-MHz electromagnetic fields does not alter rat's memory in spatial and nonspatial tasks. Behav Brain Res, 145: 51-61.

2. Andrzejak R, Poreba R, Poreba $M$, Derkacz $A$, Skalik R, Gac $P$, Beck B, Steinmetz-Beck A and Pilecki W (2008) The influence of the call with a mobile phone on heart rate variability parameters in healthy volunteers. Industrial health, $\mathbf{4 6}$ (4): 409-17.

3. Roy L, Ilan E, Ronen H, Menachem M, Nachshon M (2009) Cognitive effects of radiation emitted by cellular phones the influence of exposure side and time. Bioelectromagnetics, 30(3): 198-204.

4. Aalto $S$, Haarala $C$, Brück $A$, Sipilä $H$, Hämäläinen $H$, Rinne 


\section{Belal et al. / Mobile phone radiation-induced brain changes in rats}

JO (2006) Mobile phone affects cerebral blood flow in humans. J Cereb Blood Flow Metab, 26(7): 885-90.

5. Narayanan SN, Kumar RS, Potu BK, Nayak S, Bhat PG, Mailankot M (2010) Effect of radio-frequency electromagnetic radiations (RF-EMR) on passive avoidance behaviour and hippocampal morphology in Wistar rats. J Med Sci, 115(2): 91-96.

6. Salford G, Arne E, Jacob L, Eberhardt, M, Bertil P (2003) nerve cell damage in mammalian brain after exposure to microwaves from GSM mobile phones. Environmental Health Perspectives, 111(7): 881- 883.

7. Rasouli J, Lekhar R, White NM, Flamm ES, Pilla AA, Strauch $B$, Casper D (2012) Attenuation of interleukin-1beta by pulsed electromagnetic fields after traumatic brain injury. Neurosci Lett, 519(1): 4-8.

8. Ozguner F, Altinbas A, Ozaydin M, Dogan A, Vural H, Kisioglu AN, Cesur G, Yildirim NG (2005) Mobile phoneinduced myocardial oxidative stress: Protection by a novel antioxidant agent caffeic acid phenethyl ester. Toxicol Ind Health, 21(9): 223-230.

9. Korhonen J (2003) History of mobile cellular systems. In: Korhonen J (ed.) Introduction to $3 \mathrm{G}$ mobile communications. London: Artech House, pp. 1-8.

10. Dasdag S, Akdag MZ, Aksen F, Bashan M, Büyükbayram H. $900 \mathrm{MHz}$ GSM mobile phone exposure affect the rat brain? Electromagn Biol Med. 2004; 23: 201-214. Doi: 10.1081/ jbc-200044231

11. Hardell L, Hallquist A, Hansson Mild K, Carlberg M. Cellular and cordless telephones and the risk for brain tumours. Eur J Cancer Prev. 2002; 11: 377-386. Doi: 10.1097/00008469-200208000-00010

12. Leszczynski D, Joenvaara S, Reivinen J, Kuokka R. Nonthermal activation of the hsp27/p38MAPK stress pathway by mobile phone radiation in human endothelial cells: Molecular mechanism for cancer- and blood-brain barrier related effects. Differentiation, 2002;70:120-129. Doi: 10.1046/j.1432-0436.2002.700207.x

13. Ozben T. Oxidative stress and apoptosis: Impact on cancer therapy. J Pharmaceut Sci. 2007; 96: 2181-2196. Doi: 10.1002/jps.20874

14. Dasdag S, Akdag MZ, Ulukaya E, Uzunlar AK. Effect of mobile phone exposure on apoptotic glial cells and status of oxidative stress in rat brain. Electromagn Biol Med. 2009; 28: 342-354. Doi: 10.3109/15368370903206556

15. Belal SM, Abdel-Rahman AH, Mohamed DS, Osman HH, Hassan NA. Protective effect of pomegranate fruit juice against Aeromonas hydrophila-induced intestinal histopathological changes in mice. World Applied Sciences, 2009; 7(2):142-152.

16. Zhang LH, Li L, Li YX, Zhang YH. In vitro antioxidant activities of fruits and leaves of pomegranate. Acta Horticult, 2008;765:31-42. Doi: 10.17660/actahortic.2008.765.3

17. Toklu HZ, Sehirli O, Ozyurt H, Mayadag ${ }^{\prime l}$ AA, Eksiog lu DE, Cetinel S. Punica granatum peel extract protects against ionizing radiation-induced enteritis and leukocyte apoptosis in rats. Radiat. Res. 2009; 50:345-353.

18. Mena P, Girones-Vilaplana A, Moreno DA, GironesVilaplana C. Pomegranate fruit for health promotion:
Myths and realities. Func Plant Sci Biotech. 2011; 5:33-42.

19. Rosillo MA, Sánchez-Hidalgo M, Cárdeno A, Aparicio-Soto $M$, Sánchez-Fidalgo $S$, Villegas I. Dietary supplementation of an ellagic acid-enriched pomegranate extract attenuates chronic colonic inflammation in rats. Pharmacol Res. 2012; 66:235-42. Doi: 10.1016/j.phrs.2012.05.006

20. Whitley AC, Stoner GD, Darby MV, Walle T. Intestinal epithelial cell accumulation of the cancer preventive polyphenol ellagic acid extensive binding to protein and DNA. Biochemical Pharmacology 2003; 15(66):907-915. Doi: 10.1016/s0006-2952(03)00413-1

21. Lee SI, Kim BS, Kim KS, Lee S, Shin KS, Lim JS. Immunesuppressive activity of punicalagin via inhibition of NFAT activation. Biochemical and Biophysical Research Communications, 2008; 11(371):799-803. Doi: 10.1016/ j.bbrc.2008.04.150

22. Murthy KN, Reddy VK, Veigas JM, Murthy UD. Study on wound healing activity of Punica granatum peel. Journal of Medicinal Food 2004 ;7(3):256-259. Doi: 10.1089/1096620041224111

23. El-Rashedy AH, Belal KS, Osman HE, Shehab GM. Protective role of pomegranate on fatty liver in obesity: An experimental chemical and histopathological study. The Egyptian Journal of Hospital Medicine, 2011; 43:162-172.

24. Gil MI, Tomás-Barberán FA, Hess-Pierce B, Holcroft DM, Kader AA. Antioxidant activity of pomegranate juice and its relationship with phenolic composition and processing. Journal of Agricultural and Food Chemistry 2000; 48:45814589. Doi: 10.1021/jf000404a

25. Guo C, Wei J, Yang J, Xu J, Pang W, Jiang Y. Pomegranate juice is potentially better than apple juice in improving antioxidant function in elderly subjects. Nutr. Res. 2008; 28:72-7. Doi: 10.1016/j.nutres.2007.12.001

26. Aviram M, Dornfeld L, Rosenblat M, Volkova N, Kaplan M, Coleman R, Hayek T, Presser D, Fuhrman B. Pomegranate juice consumption reduces oxidative stress, atherogenic modifications to LDL, and platelet aggregation: studies in humans and in atherosclerotic apolipoprotein E-deficient mice. Am J Clin Nutr. 2000; 71:1062-1076. Doi: 10.1093/ ajcn/71.5.1062

27. Loren DJ, Seeram NP, Schulman RN, Holtzman DM. Maternal dietary supplementation with pomegranate juice is neuroprotective in an animal model of neonatal hypoxicischemic brain injury. Pediatr Res. 2005; 57:858-64. Doi: 10.1203/01.pdr.0000157722.07810.15

28. Naveen S, Siddalingaswamy M, Singsit D, Khanum F. Antidepressive effect of polyphenols and omega-3 fatty acid from pomegranate peel and flax seed in mice exposed to chronic mild stress. Psychiatry Clin Neurosc. 2013; 67:5018. Doi: 10.1111/pcn.12100

29. Ross HM, Pawlina W. A Text and Atlas, with Correlated Cell and Molecular Biology. 2011. p. 282-324

30. Eser O, Songur A, Aktas C, Karavelloglu E, Caglar V, Aylak F, Ozguner F, Kanter M. The Effect of Electromagnetic Radiation on the Rat Brain: An Experimental Study. Turkish Neurosurgery, 2013 ;23(6):707-715. Doi: 10.5137/10195149.jtn.7088-12.2

31. Lapornik B, Prosjek M, Wondra AG. Comparison of exInt. J. Radiat. Res., Vol. 18 No. 4, October 2020 
tracts prepared from plant by-products using different solvents and extraction time. Food Eng. 2005; 71:214-22. Doi: 10.1016/j.jfoodeng.2004.10.036

32. Bancroft JD, Gamble M. Theory and practice of Histological Techniques. 5th ed. Churchill Livingstone, 2002; p. 109136.

33. Hietanen M. Establishing the health risks of exposure to radiofrequency fields requires. multidisciplinary research. 2006; 32:169-170. Doi: 10.5271/sjweh.994

34. Mausset-Bonnefont $A$, Hirbec $H$, Bonnefont $X$, Privat $A$, Vignon J, de Seze R. Acute exposure to GSM 900-MHz electromagnetic fields induces glial reactivity and biochemical modifications in the rat. brain Neurobiol. Dis. 2004;17: 445-45. Doi: 10.1016/j.nbd.2004.07.004

35. Afeefy A, Tolba A, Afifi O K. Histological and Immunohistochemical study on the effect of mobile phone radiation on the hipocampus of adult and newborn albino rats. Nature\& science, 2013;11(8): $100-113$.

36. Chan KC, Khong PL, Cheung MM, Wang S. MRI of late microstructural and metabolic alterations in radiationinduced brain injuries. Journal of Magn Reson Imaging, 2009; 29: 1013-1020. Doi: 10.1002/jmri.21736

37. Dogan M, Turtay M G, Oguzturk H, Samdanci E, Turko Z, Tasdemir S, Alkan A, Bakir S. Effects of electromagnetic radiation produced by $3 \mathrm{G}$ mobile phones on rat brains: Magnetic resonance spectroscopy, biochemical, and histopathological evaluation. Human and Experimental Toxicology, 2012; 31(6) :557-56. Doi: $10.1177 / 0960327111412092$

38. Sokolovic D, Djindjic B, Nikolic J, Bjelakovic G, Pavlovic D, Kocic G. Melatonin reduces oxidative stress induced by chronic exposure of microwave radiation from mobile phones in rat brain. Radiat Res. 2008; 49:579-86. Doi: 10.1269/jrr.07077

39. Ilhan A, Gurel A, Armutcu F, Kamisli S, Iraz M, Akyol O. Ginkgo biloba prevents mobile phone-induced oxidative stress in rat brain. Clinica Chimica Acta. 2004; 340: 153162. Doi: $10.1016 /$ j.cccn.2003.10.012

40. Balci M, Devrim E, Durak I. Effects of mobile phones on oxidant/antioxidant balance in cornea and lens of rats. Curr Eye Res. 2007; 32:21-25. Doi: 10.1080/02713680601114948

41. Meral I, Mert H, Mert N, Deger Y. Effects of 900-MHz electromagnetic field emitted from cellular phone on brain oxidative stress and some vitamin levels of guinea pigs. Brain Res. 2007; 1169:120-124. Doi: 10.1016/ j.brainres.2007.07.015

42. Irmak MK, Fadillioglu E, Gulec M, Erdogan H. Effects of electromagnetic radiation from a cellular telephone on the oxidant and antioxidant levels in rabbits. Cell Biochem Funct. 2002; 20: 279-283. Doi: 10.1002/cbf.976

43. Sirav B1, Seyhan N. Blood-brain barrier disruption by continuous-wave radio frequency radiation. Electromagn Biol Med. 2009;28(2):215-22.

Doi: $10.1080 / 15368370802608738$

44. Stam, R. Electromagnetic fields and the blood brain barrier. Brain Res. Rev. 2010; 65(1): 80-97. Doi: 10.1016/ j.brainresrev.2010.06.001

Int. J. Radiat. Res., Vol. 18 No. 4, October 2020
45. Auer RN, Sutherl GR. Green field's Neuropathology (Hypoxia and related conditions). 7th Edition. London: Arnold; 2002; p. 233.

46. Faria A, Calhau C. The bioactivity of pomegranate: impact on health and disease. Crit Rev Food Sci Nutr. 2011; 51 (7):626-34. Doi: 10.1080/10408391003748100

47. Kam A1, Li KM, Razmovski-Naumovski V, Nammi S, Shi J, Chan K, Li GQ. A comparative study on the inhibitory effects of different parts and chemical constituents of pomegranate on $\alpha$-amylase and $\alpha$-glucosidase. Phytother Res. 2013; 27(11):1614-20. Doi: 10.1002/ptr.4913

48. Salgado MJ, Ferreira TR, Biazotto OF, Santos Dias CT. Increased antioxidant content in juice enriched with dried extract of pomegranate (Punicagranatum) peel. Plant Foods Hum Nutr. 2012; 67(1):39-43. Doi: 10.1007/s11130011-0264-y

49. Ismail T, Sestili P, Akhtar S. Pomegranate peel and fruit extracts: a review of potential anti-inflammatory and antiinfective effects. J. Ethnopharmacol. 2012; 143(2):397405. Doi: 10.1016/j.jep.2012.07.004

50. Dajas F, Rivera F, Blasina F, Arredondo F, Echeverry C, Lafon L, Morquio A, Heizen $\mathrm{H}$. Cell culture protection and in vivo neuroprotective capacity of flavonoids. Neurotox Res. 2003; 5:425-432. Doi: 10.1007/bf03033172

51. Braidy N , Selvaraju S , Essa M , Vaishnav R, Al-Adawi S, AlAsmi A , Al-Senawi H , Alobaidy A, Lakhtakia R, Guillemin J. Neuroprotective Effects of a Variety of Pomegranate Juice Extracts against MPTP-Induced Cytotoxicity and Oxidative Stress in Human Primary Neurons. Oxidative Medicine and Cellular Longevity, 2013; 12:1-12. Doi: 10.1155/2013/685909

52. Youdim KA, Spencer JP, Schroeter H, Rice-Evans C. Dietary flavonoids as potential neuroprotectants. BiolChem. 2002; 383:503-519. Doi: 10.1515/bc.2002.052

53. Subash S, Essa M, Al-Asmi A, Al-Adawi S, Vaishnav R, Braidy N, Manivasagam, T, Guillemin J. Pomegranate from Oman Alleviates the Brain Oxidative Damage in Transgenic Mouse Model of Alzheimer's Disease. Traditional and Complementary Medicine. 2014; 4:232-238. Doi: 10.4103/2225-4110.139107

54. Kaur G, Jabbar Z, Athar M, Alam M S. Pomegranate flower extract possesses potent antioxidant activity and abrogates Fe-NTA induced hepatotoxicity in mice. Food ChemToxicol. 2006; 44(7):984-93. Doi: 10.1016/ j.fct.2005.12.001

55. Lie DC, Song H, Colamarino S A, Ming G L, Gage F H. Neurogenesis in the adult brain: New strategies for central nervous system diseases. Annu Rev Pharmacol Toxicol. 2004; 44:399-421. Doi: 10.1146/ annurev.pharmtox.44.101802.121631

56. Larsson A, Wilhe Imsson U, Pekna M, Pekny M. Increased cell proliferation and neurogenesis in the hippocampal dentate gyrus by GFAP in mice. Neurochem Res. 2004; 29:2069-2073. Doi: 10.1007/s11064-004-6880-2

57. Seri B, Garcia Verdugo JM, McEwen BS, Alvarez Buylla A. Astrocytes give rise to new neurons in the adult mammalian hippocampus. Neurosci. 2001; 21(18):7153-7160. Doi: 10.1523/jneurosci.21-18-07153.2001 
58. Wang X, Xu Y, Wang F, Tang L, Liu Z, Li H, Liu S. Agingrelated changes of microglia and astrocytes in hypothalamus after intraperitoneal injection of hypertonic salinein rats. Huaz Univ Sci Technol Med Sci. 2006; 26(2):231-234. Doi: 10.1007/bf02895824

59. Lau FC, Bielinski DF, Joseph JA. Inhibitory effects of blueberry extract on the production of inflammatory media- tors in lipopolysaccharide-activated BV2 microglia. Neurosci Res. 2007; 85:1001-1010. Doi: 10.1002/jnr.21205

60. Vauzour D, Vafeiadou K, Rodriguez-Mateosm A, Rendeiro $C$, Jeremy $P$. The neuroprotective potential of flavonoids: a multiplicity of effects. Genes Nutr. 2008; 3:115-126. Doi: 10.1007/s12263-008-0091-4. 